\title{
PENGELOLAAN ADMINISTRASI SURAT MASUK DAN SURAT KELUAR UNIT KERJA BAAK BERBASIS WEB
}

\author{
Indah Kusuma Dewi \\ Teknik Informatika, STT Ibnu Sina \\ email: indah.kusuma@stt-ibnusina.ac.id
}

\begin{abstract}
Abstrak
Sekolah Tinggi Teknik (STT) Ibnu Sina Batam merupakan salah satu Perguruan Tinggi Swasta di Batam yang bertempat di Lubuk Baja. Pada STT Ibnu Sina Batam ada Bagian Administrasi Akademik (BAAK) yang menangani Persuratan yang membutuhkan data cepat dan tepat. Dalam pengelolaan surat masuk dan keluar di instansi ini masih menggunakan sistem manual sehingga prosesnya masih lambat dan kurang terjamin ketepatannya. Oleh karena itu untuk mendapatkan semua itu membutuhkan Sistem Pengelolaan Terkomputerisasi yang cepat dan tepat. Sistem Terkomputerisasi ini mengacu pada kegiatan Pengelolaan Surat Masuk dan Surat Keluar. Sistem ini dibuat dengan sistem satu user dan menggunakan program PHP dan MySQL. Dari Pengelolaan Surat Masuk dan Surat Keluar Unit BAAK STT Ibnu Sina yang dibuat, diharapkan mampu menghasilkan data yang tepat dan sesuai kebutuhan.
\end{abstract}

Kata kunci : Administrasi, Surat Masuk, Surat Keluar, Website

\begin{abstract}
The Ibnu Sina Batam Technical College (STT) is one of the Universities in Batam which is located in Lubuk Baja. At STT Ibnu Sina Batam there is an Academic Administration Section (BAAK) that handles correspondence that requires fast and precise data. In managing incoming and outgoing mail at this agency still uses a manual system so the process is still slow and the accuracy is not guaranteed. Therefore to get all of that requires a computerized Management System that is fast and precise. This computerized system refers to the activities of managing incoming and outgoing letters. This system is made with a single user system and uses PHP and MySQL programs. From the Management of Incoming and Outgoing Letters of the BAAK STT Unit Ibnu Sina, it is expected to be able to produce the right data and as needed.
\end{abstract}

Key Word : Administration, Incoming Mail, Outgoing Mail, Website

\section{PENDAHULUAN}

Surat adalah sebuah alat komunikasi tertulis yang digunakan oleh pengirim untuk mengirimkan berita atau informasi kepada penerima. Surat juga memiliki fungsi dokumentasi yang berisi rekaman tentang aktivitas suatu organisasi. Surat pula dapat dijadikan sebuah bukti atau dasar untuk melakukan tindakan tertentu karena memiliki tanda keabsahan perintah yang kuat, yaitu tanda tangan pembuatnya. Oleh karena itu penanganan pengelolaan surat perlu mendapatkan perhatian yang tinggi, terutama pada kegiatan pengarsipan untuk menjaga agar surat dapat digunakan kapan saja.

Masalah yang dihadapi saat ini di STT Ibnu Sina Batam adanya kesulitan administrasi surat masuk dan surat keluar yang tidak terstruktur dengan baik, 
sehingga berdampak kepada hilangnya surat bahkan tidak terdistribusinya surat kepada orang yang terkait. Hal ini yang mengakibatkan kesulitan manajemen untuk melakukan pendekteksian terhadap surat masuk maupun surat keluar tersebut.

Atas dasar masalah yang dialami diatas, manajemen berupaya melakukan perbaikan bahkan sampai dengan dibuatnya aturan dan pengalokasisan petugas, namun dikarenakan banyaknya jumlah surat yang masuk dan surat yang keluar hal ini masih tidak dapat menjawab masalah diatas tersebut.

Kendala lainnya saat ini dalam pelaksanaannya pengelolaan surat banyak mengalami kendala. Seperti pada saat pengagendaan surat masuk yang diterima dan surat keluar yang akan dikirimkan, penomoran surat sulit dilakukan karena surat dicatat pada buku agenda konvensional. Pengarsipan dokumen fisik surat belum optimal, terutama pada saat pencarian berkas arsip surat membutuhkan waktu cukup lama karena posisi penyimpanan arsip surat bercampur dan tidak memiliki pengkodean khusus. Serta distribusi surat keluar yang bersifat edaran di internal STT Ibnu Sina membutuhkan waktu yang yang cukup lama dan biaya lebih, karena harus digandakan terlebih dahulu untuk kemudian disampaikan kepada penerima surat.

\section{METODE PENELITIAN}

\subsection{Pengelolaan}

Pengelolaan adalah proses yang membantu merumuskan kebijakan dan tujuan organisasi atau proses yang memberikan pengawasan pada suatu hal yang terlibat dalam pelaksanaan kebijakan dan pencapaian tujuan. Pengelolaan berasal dari kata kelola dan merupakan terjemahan dari kata manajement (Bahasa Inggris). Terbawa oleh derasnya arus penambahan kata pungut ke dalam bahasa Indonesia, istilah Ingris tersebut lalu menjadi Manajemen atau manejemen.

\subsection{Administrasi}

Pada dasarnya administrasi melingkupi seluruh kegiatan dari pengaturan hingga pengurusan sekelompok orang yang memiliki diferensi pekerjaan untuk mencapai suatu tujuan bersama. Administrasi dapat berjalan dengan adanya banyak orang terlibat di dalamnya. Hal ini sesuai dengan pengertian administrasi yang dapat dibedakan menjadi dua bagian yang dikemukakan oleh Irra Chisyanti Dewi pada jurnal Rachmatsyah dkk (2017).

\subsection{Metode Pengumpulan Data}

Dalam pengumpulan data ini menggunakan beberapa cara dalam mengkaji dan memahami permasalahan yang ada, yaitu:

\section{Studi Pustaka}

Metode studi pustaka adalah suatu teknik atau cara pengumpulan data atau informasi yang dilakukan dengan cara membaca jurnal, laporan-laporan yang berhubungan dengan masalah terkait.

2. Wawancara

Pada tahapan wawancara, teknik pengumpulan data dengan melakukan tanya jawab secara langsung dengan Unit BAAK, dalam metode ini peneliti mewawancarai Bapak Sabtu, S.Kom, M.Pd.T selaku Kepala Unit BAAK (Biro Administrasi Akademik dan Kemahasiswaan) Sekolah Tinggi Teknik (STT) Ibnu Sina Batam.

3. Observasi

Pada tahap ini, teknik pengumpulan data dengan melakukan pengamatan langsung terhadap objek penelitian 
dengan mencatat hal-hal penting yang berhubungan dengan penelitian di Sekolah Tinggi Teknik (STT) Ibnu Sina Batam.

\section{Data Penelitian}

Pada tahap ini, data-data yang sudah ada akan diteliti lebih lanjut agar dapat menyelesaikan masalah yang akan di teliti.

\section{Mekanisme Penelitian}

Pada tahap mekanisme penelitian, data yang ada akan diklasifikasikan menjadi manual data dan komputerisasi. Manual data berupa laporan dari penelitian dan komputerisasi berupa program yang dibuat berdasarkan dari penelitian.

6. Dokumen Penelitian

Dokumen penelitian Sekolah Tinggi Teknik (STT) Ibnu Sina Batam merupakan laporan dari hasil penelitian.

\subsection{Metode Perancangan Sistem}

Pada Analisa dan Pengembangan Sistem ini menggunakan metode Object Oriented Analysis and Design atau yang disebut OOAD

a. Konsep Object Oriented Analysis and Design (OOAD)

Metodologi Booch's Object Oriented Analysis dan Design, selanjutnya disingkat OOAD, merupakan penggabungan 3 (tiga) pendekatan, yaitu: Object Oriented Design (OOD), Object Oriented Analysis (OOA) dan Object Oriented Programming (OOP).

OOA merupakan metode analisis yang memeriksa kebutuhan (requirement) berdasarkan prespektif pengumpulan obyek-obyek dan kelas-kelas dalam sebuah domain problem, sedangkan OOD merupakan sebuah metode mendesain yang mencakup proses pendekompoisisan obyek dan digambarkan dalam notasi sehingga bisa menggambarkan static dan dynamic model sistem baik secara logical dan/atau physical (Booch, et al, 2007: 42). Berdasarkan pengertian ini, ada 2 (dua) hal penting yang harus ditekankan dalam OOD, yaitu:

1. OOD menggunakan teknik object oriented decomposition.

2. Menggunakan notasi yang berbeda untuk menggambarkan model logical struktur obyek dan kelas, dan model physical dari arsitektur modul dan proses dalam sebuah aspek sistem baik statis maupun dinamis.

OOP merupakan sebuah metode untuk mengimplementasikan program yang diorganisasikan sebagai kumpulan obyek dimana tiap-tiap obyek merupakan instan dari sebuah kelas dan kelas merupakan salah satu dari kumpulan kelas yang saling berhubungan secara hirarki menggunakan inheritance relationship (Booch, et al, 2007: 41). Berdasarkan pengertian ini, ada 3 (tiga) hal penting yang harus ditekankan dalam OOP, yaitu:

1. OOP menggunakan obyek sebagai dasar dalam membangun program, bukan algoritma.

2. Obyek merupakan instan dari sebuah kelas

3. Setiap kelas dihubungkan menggunakan inheritance relationship atau yang kita kenal dengan istilah pewarisan, sehingga bahasa pemograman yang tidak mendukung inheritance tidak bisa mengimplementasikan OOP.

Hubungan antara OOA, OOD dan OOP adalah: hasil pemodelan atau pengumpulan obyek dari OOA akan digunakan oleh OOD dan hasil dari OOD akan digunakan sebagai blueprint untuk membangun sistem dengan menggunakan OOP

b. Tahapan-tahapan OOAD 
1. Requirement

Pada tahap requirement menjelaskan tentang bagaimana membuat dan menjaga sebuah perjanjian kerasama dengan customer dan stakeholder mengenai apa yang harus dilakukan pada pembuatan sistem, misalnya kebutuhan-kebutuhan dari suatu sistem seperti fungsi-fungsi apa saja yang akan diunakan oleh sistem, fiturfitur apa saja yang akan dipakai dalam pembutan sistem, siapa saja user yang terlibat atau yang memakai sistem tersebut dan lain sebagainya. Selain itu, tahapan ini juga mendefinisikan batasan-batasan dari suatu sistem yang akan dibuat.

2. Analysis and Design

Tahapan ini menjelaskan bagaimana mengkonversi kebutuhan- kebutuhan sistem yang telah dibuat sebelumnya menjadi sebuah bentuk rancangan sistem. Yang mana rancangan tersebut disajikan sebagai spesifikasi dari implementasi sistem dalam memilih lingkungan penerapannya. Selain itu, tahapan analisis dan desain juga mencakup dalam mengembangkan sebuah arsitektur/bentuk rancangan yang kokoh untuk sebuah sistem dan menetapkan mekanisme umum yang harus digunakan oleh elemenelemen yang berbeda dari sistem.

3. Implementation

Setelah membuat suatu kebutuhan sistem, menganalisis dan merancang sistem yang akan dibuat. Kemudian pada tahap ini dilakukan implementasi unit sistem dan menggabungkan rancangan dengan sistem, maksudnya adalah mengimplementasikan rancangan tersebut dalam sebuah sistem atau program dalam bentuk coding program. Selain itu juga menghasilkan sebuah sistem yang sudah dapat dijalankan.

\section{Pengujian (Test)}

Tes/pengujian dilakukan untuk meyakinkan bahwa sistem telah sesuai dengan kebutuhan-kebutuhan yang telah dibuat sebelumnya (kebutuhan-kebutuhan tersebut adalah menerapkan yang sewajarnya). Memvalidasi fungsi sistem yang telah konkrit kemudian didemonstrasikan bahwa produk software tersebut sesuai dengan kebutuhan dan rancangan yang telah dibuat sebelumnya

5. Deployment

Meyakinkan bahwa produk software tersebut (termasuk implementasi dan pengujian) telah tersedia untuk end user atau sudah dapat digunakan oleh pengguna akhir. Proses makro memiliki aktivitas-aktivitas pendukung di dalam pembuatan software-nya yang mencakup Project Management, Configuration and Change Management dan Environment.

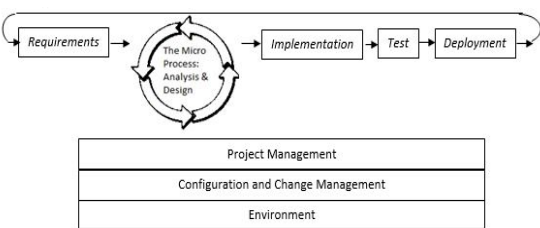

\section{Gambar 1. Tahapan Object Oriented Analysis and Design (OOAD)}

\section{HASIL DAN PEMBAHASAN HASIL}

1. Layout login

Adalah halaman yang pertama kali muncul saat alamat situs diakses. Pada halaman depan login terlebih dahulu sebagai admin atau sebagai staff. Gambar layout login dapat dilihat seperti pada gambar 2.

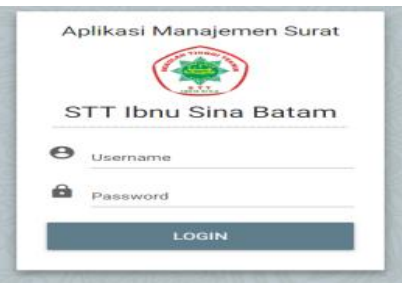

Gambar 2. Layout Login

https://ejournal.stmikgici.ac.id/ STMIK GICI 
2. Layout Halaman Utama admin Layout halaman utama admin yaitu Dashboard. dapat di lihat pada gambar 3.

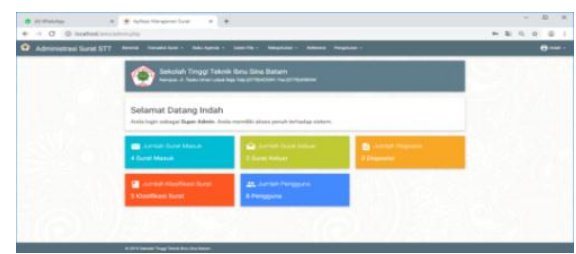

\section{Gambar 3. Layout Halaman Utama}

3. Layout Tentang Surat Masuk

Layout Tentang Surat masuk yaitu: Dimana admin dapat melihat dan mendownload surat masuk.yang dapat di lihat pada gambar 4 .

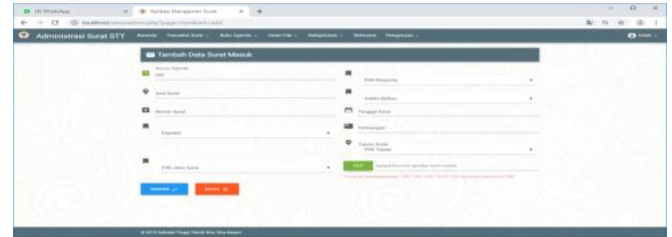

\section{Gambar 4. Layout Surat Masuk}

4. Layout Surat Keluar

Layout Surat Keluar berisikan data Surat keluar. dapat di lihat pada gambar 5

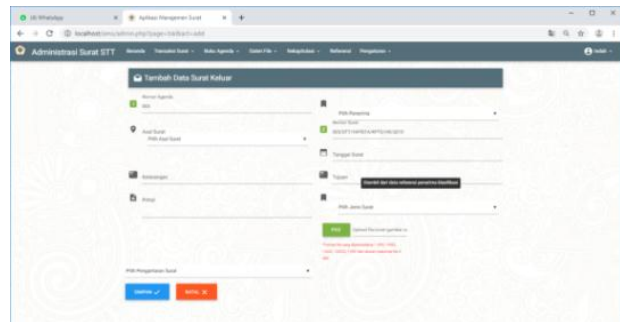

\section{Gambar 5. Layout Surat Keluar}

5. Layout Galeri Surat Masuk

Layout Galeri Surat Masuk, dapat di lihat padagambar 6 .

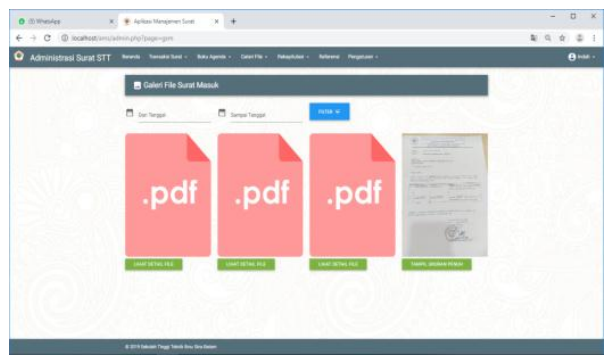

Gambar 6. Layout Galeri Surat Masuk
6. Layout Galeri Surat Keluar Layout Agenda Surat Keluar, dapat di lihat padagambar 7 .

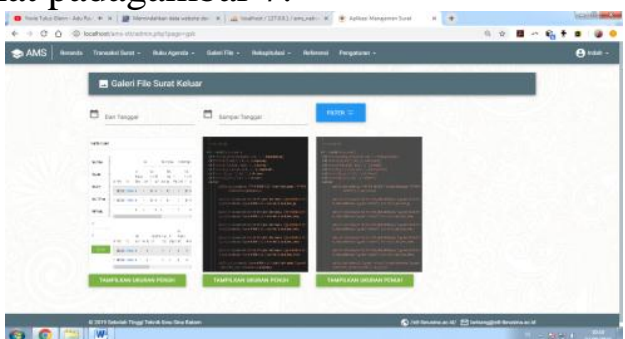

\section{Gambar 7. Layout Galeri Surat Keluar}

7. Layout Rekapitulasi Surat Masuk Layout Rekapitulasi Surat Masuk, dapat di lihat padagambar 8 .

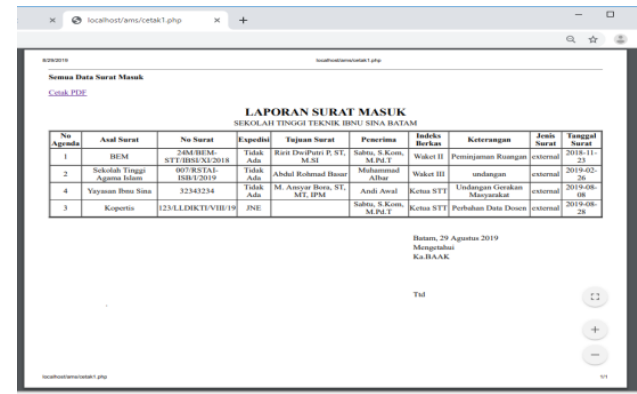

\section{Gambar 8. Layout Rekapitulasi} Surat Masuk

8. Layout Rekapitulasi Surat Keluar

Layout Rekapitulasi Surat Keluar, dapat di lihat padagambar 4.17

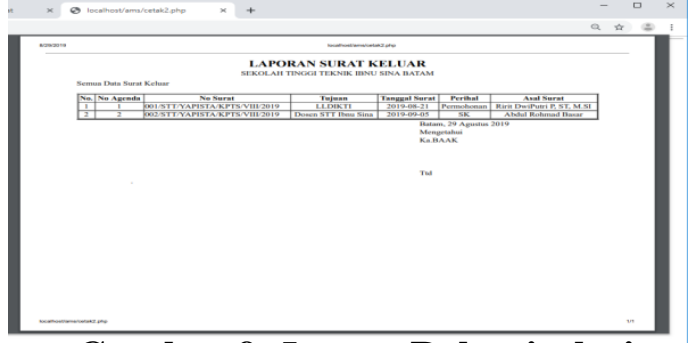

Gambar 9. Layout Rekapitulasi Surat Keluar

\section{PEMBAHASAN}

3.1. Pengumpulan Data

Berdasarkan observasi yang dilakukan oleh penulis pada Sekolah Tinggi Teknik (STT) Ibnu Sina Batam Unit BAAK diperoleh data yang akan 
diolah untuk sistem yang akan dirancang.

Data tersebut meliputi sebagai berikut:

Data primer yang di dapatkan dari hasil wawancara secara mendalam sebagai berikut:

1. Rekapan surat yang akan digunakan pada penelitian yang digunakan pada pengelolaan administrasi adalah: surat tugas, surat keputusan, surat mengajar

2. Tampilan desain user interface pengelolaan administrasi surat masuk dan surat keluar unit BAAK Pada Sekolah Tinggi Teknik (STT) Ibnu Sina Batam.

Data sekunder yang didapatkan dari hasil observasi secara lansung sebagai berikut:

1. Profile Sekolah Tinggi Teknik (STT) Ibnu Sina Batam

2. Data Surat Sekolah Tinggi Teknik (STT) Ibnu Sina Batam.

\subsection{Pengembangan Sistem}

Metode yang digunakan dalam pengembangan sistem adalah metode Object Oriented Analysis and Design (OOAD) dengan metode pemodelan UML (Unified Modeling Languange).

\subsection{Analysis dan Design}

Selanjutnya setelah penentuan requirement maka peneliti menganalisa permasalahan yang dihadapi pada Kampus STT Ibnu Sina Batam. Pada tahap ini dibuat sesuai kebutuhan admin dan user pada Unit BAAK Sekolah Tinggi Teknik (STT) Ibnu Sina Batam. Tahap pada sistem ini menggunakan tahapan UML (Unified Modeling Languange).

Setelah melakukan analisis sistem, maka yang dilakukan berikutnya adalah melakukan tahap design yang nantinya akan dikerjakan atau digambarkan dalam bentuk dashboard dengan menggunakan pemodelan UML. Pada umumnya tujuan dari perancangan sistem informasi ini adalah :

1. Untuk memenuhi kebutuhan pemakaian sistem di Sekolah Tinggi Teknik (STT) Ibnu Sina Batam.

2. Memberikan gambaran yang jelas dan rancangan lengkap dalam membuat web.

3. Perancangan sistem harus efektif dan efisien untuk mendukung pengelolaan administrasi surat masuk dan surat keluar pada Sekolah Tinggi Teknik (STT) Ibnu Sina Batam.

Untuk mencapai harapan tersebut, rancangan sistem informasi ini akan menggunakan pemodelan UML mulai dari Usecase Diagram, Activity Diagram. Sequence Diagram. Class Diagram, dan rancangan database sistem yang akan dibuat.

\section{Use Case Diagram}

Use Case adalah konstruksi untuk mendeskripsikan bagaimana sistem terlihat dimata pengguna. Sasaran pemodelan Use Case diantaranya adalah mendefinisikan kebutuhan fungsional dan operasional sistem dengan mendefinisikan skenario penggunaan yang disepakati antara pemakai (user) dan pengembang (admin).

a. Use Case Admin

Admin adalah actor yang berperan dalam menyediakan semua kebutuhan user dan staff yang memiliki peranan dalam keberhasilan operasi dari sistem, sehingga admin harus melakukan aktifitas maintenance sistem agar aktifitas user dapat berjalan dengan baik. 


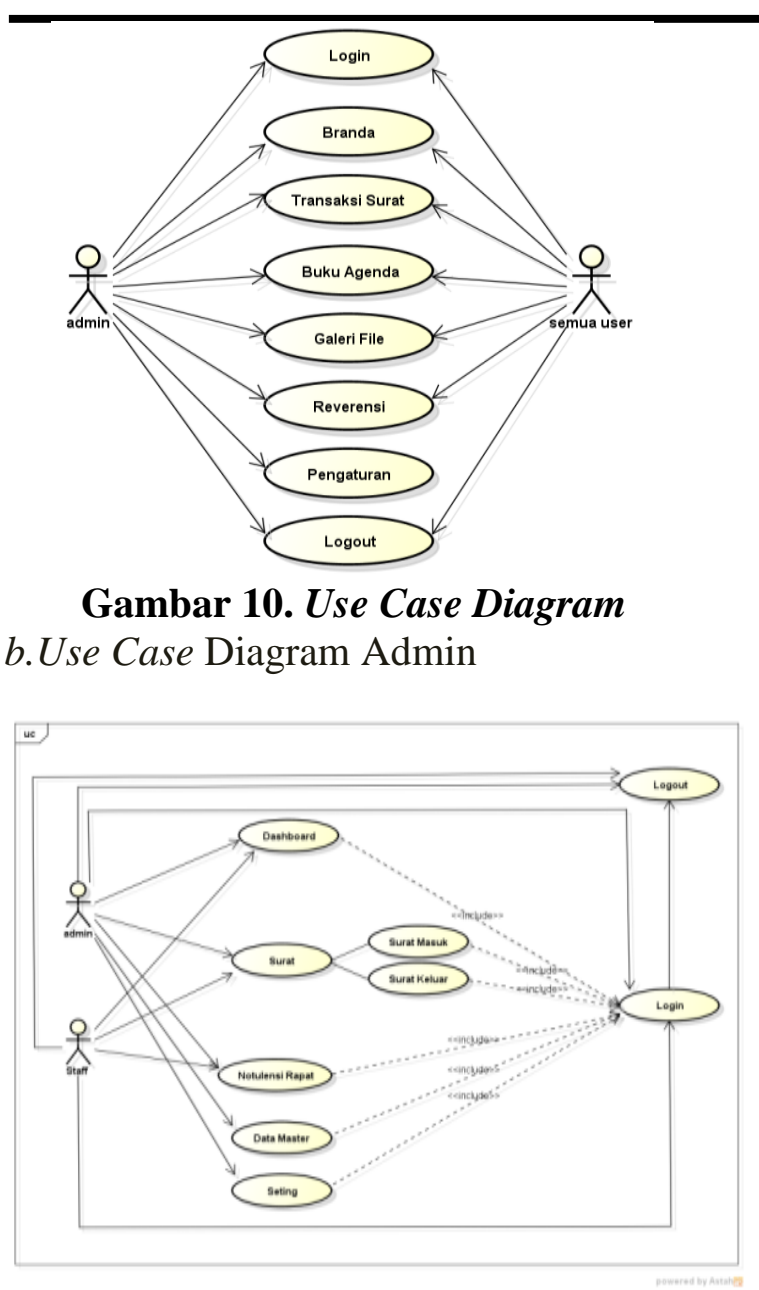

\section{Gambar 11. Usecase Diagram Admin}

Penjelasan dari rancangan usecase diagram Admin pada Sekolah Tinggi eknik (STT) Ibnu Sina Batamyaitu:

1. Admin memiliki akses penuh untuk mengolah data surat masuk, surat keluar, dan data master.

2. Admin memiliki akses penuh untuk melihat hasil tampilan dashboard yang sudah jadi.

\section{Activity Diagram}

Activity diagram merupakan sebuah diagram dimana dalam diagram tersebut terdapat semua aktivitas dalam sistem informasi Surat masuk dan surat kelur. Dalam activity diagram digambarkan aktivitas dari setiap aktor yang ada.

\section{a. Activity Diagram Admin}

Activity diagram Admin menggambarkan aktivitas penambahan, penghapusan, dan pengeditan yang dilakukan Admin terhadap system dengan melakukan login terlebih dahulu. Rancangan Activity Diagram Admin dapat dilihat pada gambar 12 berikut ini :

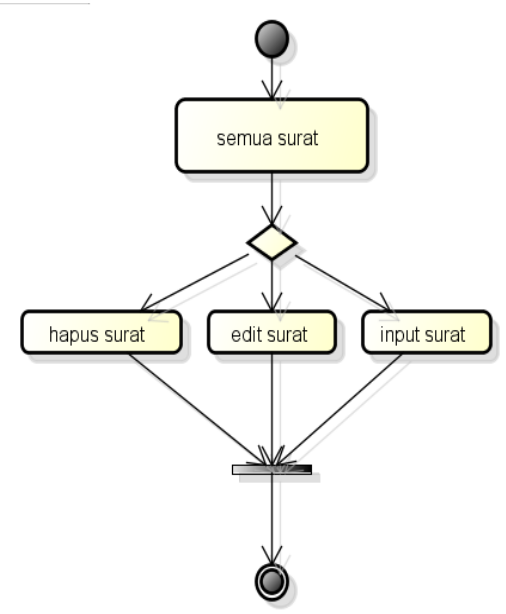

\section{Gambar 12. Activity Diagram Admin}

\section{b. Activity Diagram user}

Activity diagram user menggambarkan aktivitas meliaht surat masuk dan surat keluar serta melihat notulen rapat, yang dilakukan user terhadap system dengan melakukan login terlebih dahulu. Rancangan Activity Diagram user dapat dilihat pada gambar 13 berikut ini : 


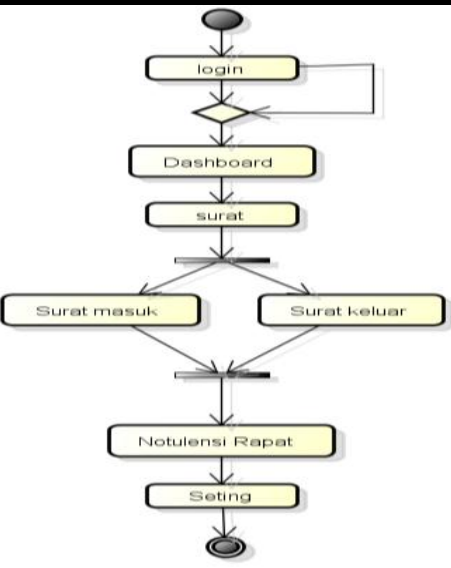

Gambar 13 Activity Diagram Staff

\section{Sequence Diagram}

Sequence diagram digunakan untuk menggambarkan perilaku aktor pada sebuah sistem secara detail menurut waktu. Diagram ini menunjukkan sejumlah contoh objek dan message (pesan) yang diletakkan diantara objekobjek di dalam use case.

a. Sequence Diagram Admin

Diagram ini menjelaskan urutan langkah-langkah yang dapat dilakukan oleh admin kedalam sistem dapat dilihat pada gambar 14 .

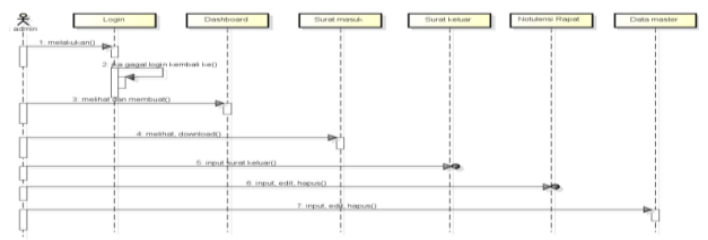

\section{Gambar 14. Sequence Diagram Admin}

\section{b. Sequence Diagram Staff}

Diagram ini menjelaskan urutan langkah-langkah yang dapat dilakukan oleh staff kedalam sistem untuk kategori dapat dilihat pada gambar 4.5

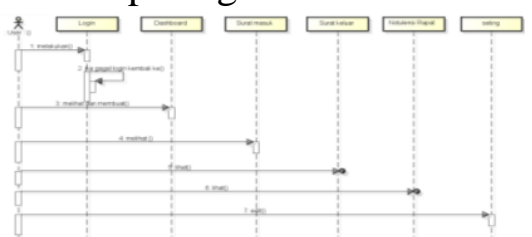

Gambar 15. Sequence Diagram Staff
4. Class Diagram

Class diagram adalah sebuah spesifikasi yang akan menghasilkan sebuah objek dan merupakan inti dari pengembangan dan desain berorentasi objek. Class diagram juga menggambarkan struktur suatu sistem dengan menunjukkan class dan hubungannya, adapun interaksinya dapat dilihat pada gambar 16 .

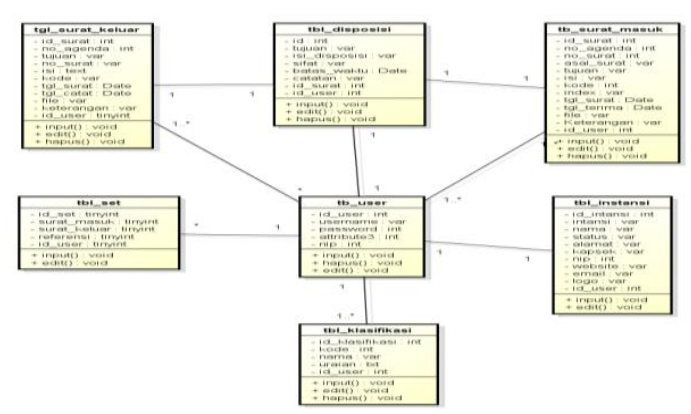

Gambar 16. Class Diagram

\section{SIMPULAN}

Berdasarkan penelitian yang telah dilaksanakan, penulis menarik kesimpulan sebagai berikut :

1. Sistem yang dirancang ini adalah sistem informasi pengelolaan surat masuk dan surat keluar. Dalam perancangan sistem dirancang untuk dapat melakukan pengelolaan surat masuk, surat keluar, disposisi surat dan pengarsipan surat digital dengan penomoran otomatis.

2. Implementasi dari perancangan sistem informasi pengelolaan surat masuk dan surat keluar ini dilaksanakan dengan cara membuat kode program dengan menggunakan bahasa pemrograman. Sehingga menghasilkan sebuah sistem informasi pengelolaan surat masuk dan surat keluar pada Sekolah Tinggi 
Teknik (STT) Ibnu Sina Batam yang utuh.

3. Pengujian yang dilakukan terhadap setiap fungsi sistem dengan menggunakan pengujian aplikasi dengan menunjukkan hasil yang baik. Karena setiap fungsi yang dibuat dapat digunakan dengan baik dan sesuai dengan kebutuhan.

\section{UCAPAN TERIMA KASIH}

Ucapan terimakasih kami sampaikan kepada Ketua Yayasan Pendidikan Ibnu Sina (YAPIS) yang memberikan bantuan dana sehingga penelitian ini dapat berjalan dengan baik. Kami ucapkan juga terimakasih kepada Bapak Ketua STT Ibnu Sina, LPPM dan dosen-dosen lainnya yang terlibat sehingga kegiatan penelitian ini berjalan sebagaimana mestinya.

\section{DAFTAR PUSTAKA}

Anwar, S., Efendi, Y., Rustam, R., \& Andrew, A. (2016). Perancangan Sistem Informasi Pendaftaran Mahasiswa Baru dan Pengisian Kartu Rencana Studi (KRS) AMIK Wahana Mandiri Berbasis Web Mobile. Studia Informatika: Jurnal Sistem Informasi, 9(1).

AP, Denny Rianditha. (2019). Location Based Service Bengkel dengan Client-Servre. Jurnal Sistem Informasi Universitas Suryadarma, 6(1).

Booch, et al. 2007 : Object-Oriented Analysis And Design, ISBN 0-80535340-2, 151617181920 DOC 01 0099 98, l5th Printing December 1998.
Haryanto, D., \& Nasihin, A. (2018). Sistem Informasi Kearsipan Surat Masuk Surat Keluar di STIKes Mitra Kencana Kota Tasikmalaya. Hendini, Ade (2016). Pemodelan UML Sistem Informasi Monitoring dan Stok Penjualan Barang (Studi Kasus: Distro Zhezha Pontianak). Jurnal Khatulistiwa Informatika, Vol. IV, No.2.

Dewi, K. I., \& Syofiawan, D., \& Grace, T. U (2018). Pembangunan Dashboard Sebagai Alat Monitoring dan Evaluasi Pada Toko Permata Batam. Jurnal Responsive, Vol 2, No.2.

Masykur, F., \& Atmaja, I. M. P (2015). Sistem Administrasi Pengelolaan Arsip Surat Masuk dan Surat Keluar Berbasis Web. IJNS (Indonesian Jurnal On Networking And Security), Vol.4 No.3.

Rachmatsyah, A. D., \& Merlini, D. (2017). Perancangan Sistem Informasi Administrasi Surat Berbasis Desktop Pada Kantor Notaris Hoiril Masuli, Sh, M. Kn. Jurnal Sisfokom (Sistem Informasi dan Komputer), 6(2), 130-136.

Rakhmah, A. H., \& Alrasyid, M. I. (2018). Perancangan Sistem Informasi Seleksi Karyawan pada pt. Prawathiya Karsa Pradiptha Bekasi. Jurnal Lentera ICT, 4(1), 21-33.

Rizaldi, R., Anggraeni, D., \& Syah, A. Z. (2018). Tips Dan Trik Membangun Relationship Dan Query Dalam Database. Jurdimas (Jurnal Pengabdian Kepada Masyarakat) Royal, 1(2), 45-50.

Ropianto, M. (2016). Pemahaman Penggunaan Unified Modelling 
Language. Jurnal Teknik Ibnu Sina JT-IBSI, I(01).

Ropianto, M. (2017). Architecture Information Design Of Internal Quality Assurance Agency STT Ibnu Sina Batam Using Enterprise Architecture Planning (EAP). ASIA International Multidisiplin Conference 2017.

Saputra, K. A., \& Famukhit. M. L ( 2014). Perancangan Sistem Informasi Surat Masuk dan Surat Keluar Pada MTs Guppi Jetiskidul. IJNS (Indonesian Jurnal On Networking And Security, Vol.3, No.4.

Santosa, A. T. D. (2015). Sistem Informasi Administrasi Surat Masuk dan Surat Keluar pada Badan Kepegawaian Daerah Kota Semarang.

Saragih, F. N. Y., \& Damanik, R. (2018). Sistem Informasi Administrasi Surat Masuk Dan Surat Keluar Pada Biro Rektorat Universitas Katolik Santo Thomas Medan. MEANS (Media Informasi Analisa dan Sistem), 3(1), 62-68.

Sinta Maulina, F. I. R. D. A. U. S. (2019). Pengembangan Aplikasi Radio Streaming Dan On-Demand Berbasis Website Di Radio Suara Bangkalan FM. Jurnal Manajemen Informatika, 9(2).

Suendri (2018). Implementasi Diagram UML (Unified Modelling Language) Pada Perancangan Sistem Informasi Remunerasi Dosen Dengan Database Oracle. Jurnal Ilmu Komputer dan Informatika, Vol.3, No.1.

Sugiarto, M. I., Linarta, A., \& Sofiyan, A. (2017). Aplikasi Layanan Informasi Absen dan Nilai Berbasis SMS Gayeway Menggunakan PHP pada
SMK Taruna Persada

Dumai. Informatika, 9(2), 60-69.

Sutanti, D., \& TJ. T. I (2013). Pembuatan Website Profile Sekolah Menengah Pertama Negeri 2 Kerjo Kabupaten Karanganyar. Seminar Riset Unggulan Nasional Informatika dan Komputer FTI UNSA.

swdmyinside.https://swdinside.blogspot.c om/2015/11/pengertianpengelolaan .html

Widodo, M,R,R., \& Zainuddin, M. (2016). Sistem Informasi Dan Pengolahan Data Kursus Mobil Berbasis WEB Dengan Sms Gateway Di Armada Pasuruan. Jurnal Informatika Merdeka Pasuruan. Jurnal teknik Vol.1(2), ISSN: 2503-1945. 